J Neurol. 2013 July ; 260(7): 1880-1888. doi:10.1007/s00415-013-6898-y.

\title{
The Alien Limb Phenomenon
}

\author{
Jonathan Graff-Radford, MD ${ }^{1}$, Mark N Rubin, MD ${ }^{1}$, David T. Jones, MD², Allen J. Aksamit, \\ MD ${ }^{1}$, J. Eric Ahlskog, PhD MD ${ }^{1}$, David S. Knopman, MD ${ }^{1}$, Ronald C. Petersen, MD, PhD ${ }^{1}$, \\ Bradley F. Boeve, MD ${ }^{1}$, and Keith A. Josephs, MD MS ${ }^{1}$ \\ ${ }^{1}$ Department of Neurology, Mayo Clinic, Rochester, Minnesota, USA \\ ${ }^{2}$ Department of Radiology Research, Mayo Clinic, Rochester, Minnesota, USA
}

\section{Abstract}

Background-Alien limb phenomenon refers to involuntary motor activity of a limb in conjunction with the feeling of estrangement from that limb. Alien limb serves as a diagnostic feature of corticobasal syndrome.

Objective-Our objective was to determine the differential diagnoses of alien limb and to determine the features in a large group of patients with the alien limb with different underlying etiologies.

Methods-We searched the Mayo Clinic Medical Records Linkage system to identify patients with the diagnosis of alien limb seen between January 1, 1996, and July 11, 2011.

Results-One hundred fifty patients with alien limb were identified. Twenty two were followed in the Alzheimer's Disease Research Center. Etiologies of alien limb included corticobasal syndrome $(n=108)$, stroke $(n=14)$, Creutzfeldt Jacob disease $(n=9)$, Hereditary diffuse leukoencephalopathy with spheroids $(n=5)$, tumor $(n=4)$, progressive multifocal leukoencephalopathy $(n=2)$, demyelinating disease $(n=2)$, progressive dementia not otherwise specified $(n=2)$, posterior reversible encephalopathy syndrome $(n=1)$, corpus callosotomy $(n=1)$, intracerebral hemorrhage $(n=1)$ and thalamic dementia $(n=1)$. Ten of fourteen cerebrovascular cases were right hemisphere in origin. All cases involved the parietal lobe. Of the 44 patients with corticobasal syndrome from the Alzheimer's Disease Research Center cohort, 22 had alien limb, and $73 \%$ had the alien limb affecting the left extremities. Left sided corticobasal syndrome was significantly associated with the presence of alien limb $(\mathrm{p}=0.004)$.

Conclusions-These findings support the notion that the alien limb phenomenon is partially related to damage underlying the parietal cortex, especially the right parietal, disconnecting it from other cortical areas.

\section{Keywords}

Alien limb; corticobasal syndrome

\section{Introduction}

The alien limb, as defined by Doody and Jankovic [13], is characterized by an extremity that "is foreign" or 'has a will of its own,' together with observable involuntary motor activity.

Corresponding Author: Keith A. Josephs, MD, MST, MSc, Professor of Neurology, Mayo Clinic, 200 1st Street SW, Rochester, MN 55905, Tele: (507)-538-1038, Fax: (507)538-6012, Josephs.keith@ mayo.edu.

Conflict of interest:

The authors declare that they have no conflict of interest. 
This phenomenon has intrigued physicians since its original description over 100 years ago [19]. The sense of estrangement was not emphasized or even recognized until 1972 [8], when Brion and Jedynak described the main étrangère, or "strange hand." They categorized this as a sensory disconnection syndrome and specifically a sign of callosal disconnection, noting the patients' inability to recognize their own hand when both hands were placed out of view (behind the back, or in front of the patient with closed eyes). Later Wilson et al offered an alternative name to the sign, "the stranger's hand sign", emphasizing the feeling of estrangement from one's limb[39]. The term alien hand was introduced by Bogen as the result of a misinterpretation of Brion and Jedynak's paper [6, 40]. He expanded the definition to include undesired movements, redefining it as an action. In the decades between these descriptions and to the present, there has been an effort to better characterize this phenomenon in numerous disparate clinical scenarios, including stroke [1, 2, 9-11, 13, 14, 16-18, 21, 26, 28, 29, 32, 37, 38], corticobasal syndrome (CBS) [13, 15, 25], progressive supranuclear palsy [4], Alzheimer's disease [3] and Creutzfeldt-Jakob disease (CJD) [22, 30, $31,35]$. Whereas alien limb phenomenon is typically described in one of the upper extremities, alien limb can also manifest in the lower extremity [23].

Earlier reports focused on alien limb as the result of callosal lesions. The anatomical studies $[10,14,17,28]$ involved mostly patients with anterior cerebral artery strokes, ischemic or hemorrhagic, that affected the genu of the corpus callosum with or without destruction of medial frontal structures. One unique case of nonfluent progressive aphasia to corticobasal syndrome demonstrated spreading of atrophy to the medial frontal lobe and bilateral basal ganglia coinciding with the appearance of alien limb.[20] As more manuscripts were published it became apparent that the presentation of alien limb came in several clinical phenotypes and an attempt was made to separate these patients based on lesion localization and clinical phenotypes. [14]. Rigid classifications have since come into question [37].

Recent reports detail the posterior alien limb phenotype, featuring coexisting rigidity, apraxia, cortical sensory findings, neglect and prominent estrangement from the limb. This variation has been termed the posterior alien limb and has been described in several diseases, most commonly in corticobasal syndrome (CBS) [13, 15, 25], but also in stroke[26], Creutzfeldt-Jakob disease [30,35]. The alien limb in CBS was more associated with limb elevation and abnormal posturing that than seen in disease processes affecting predominantly the frontal lobes or corpus callosum. Denny-Brown et al. described the phenomenon of levitation in parietal lobe lesions [12], although Riley et al. noted in one of the first clinical descriptions of CBS that the alien limb in CBS was similar to that described in lesions of the supplementary motor area [34].

The myriad of reports of alien limb cited above demonstrate that individual cases often defy exact classification, with considerable overlap of clinical, radiographic and pathologic findings. These findings, in the setting of decades of focused research attention failing to pinpoint a lesional "center," suggest that the quest for an individual clinical definition or neuroanatomic correlate to the alien limb is Sisyphean. However, the alien limb is used as an important feature in the diagnosis of CBS.

No prior studies have systemically assessed the occurrence of alien limb across a number of different etiologies and, thus, neuroanatomic locations. The aim of our study therefore was to determine the clinical and demographic features of a large number of subjects with the alien limb spanning all possible etiologies with an emphasis on the clinical features of those with CBS and alien limb. 


\section{Methods}

\section{Participants}

Using the Mayo Clinic Medical Records Linkage System, we identified all patients with diagnoses of alien limb seen within the Department of Neurology between January 1, 1996, and July 11, 2011. The computer search strategy employed the text words "alien hand," "anarchic hand," "alien," and "mind of its own" crossed referenced with Department of Neurology. We identified 452 patients using this search strategy. The medical records of these 452 patients were reviewed to determine whether the patients met the Doody-Jankovic diagnostic criteria: the patient experiences that an extremity "is foreign or "has a will of its own,' together with observable involuntary motor activity [13]. Exclusion criteria included age less than 18 or features associated with alien limb such as mirror movements or arm levitation without meeting full Jankovic criteria. Of these 452 patients, 180 were thought to have features of alien limb syndrome. However, thirty patients were excluded because the documentation was insufficient to be certain whether they fulfilled clinical criteria, leaving a total of 150 patients with alien limb. Twenty-two of the 150 cases had been followed longitudinally in the Mayo Clinic Alzheimer's Disease Research Center (ADRC). All patients consented to the use of their clinical records for the purpose of research and the study was approved by the Mayo ClinicInstitutional Review Board, and have, therefore, been performed in accordance with the ethical standards laid down in the 1964 Declaration of Helsinki and its later amendments.

All cases of CBS (with and without alien limb) in the ADRC were included used to determine the frequency of alien limb in CBS. A total of 44 patients with CBS had been evaluated by Mayo ADRC staff at least once.

Clinical data abstracted for all patients included age at onset of alien limb, description of alien limb, associated exam findings, gender, handedness, side of alien limb, first and final clinical diagnosis, physical/neurological findings on examination, imaging studies and any treatment received. Corticobasal syndrome (CBS) was defined as the classic clinical syndrome originally described by Rebeiz, et al.[33], characterized by progressive asymmetric limb rigidity and apraxia, but allowing for overlap with other related syndromes; such as vertical gaze palsy/falls seen in progressive supranuclear palsy or aphasia seen in primary non-fluent aphasia. A chi-square analysis was performed to determine whether CBS laterality was associated with alien limb.

\section{Imaging}

All cases with stroke as the etiology for alien limb that had adequate quality structural MRI available were used for the lesion mapping analysis. The sequences acquired around the time of symptomonset, with clinically-attributable infarction signal change were utilized. The unified segmentation and normalization procedure of SPM5 (Wellcome Department of Cognitive Neurology, Institute of Neurology, University College London, UK) was used to normalize every scan of interest to the ICBM template. Regions of interest (ROI) were then manual outlined for each subject's zone of infarction using MRIcron (http:// www.mccauslandcenter.sc.edu/mricro/mricron/). For simultaneous viewing of all 9 cases, the ROIs were overlaid on the template brain (Figure 1A). A map of the regional involvement across all of the subject's zones of infarction was created by combining all of these ROIs into a single frequency map (Figure1B) and displayed on a surface rendering using Caret software (http://www.nitrc.org/projects/caret/). 


\section{Results}

Subjects

The demographic features are summarized in Table 1. The most common cause of alien limb syndrome was CBS $(n=108)$. Of the cases of CBS there was clinical overlap between CBS and other clinical presentations. Thirteen cases overlapped with PSP, seven with posterior cortical atrophy, two with primary progressive aphasia, and four had features of a presumed synucleinopathy (multiple system atrophy or dementia with Lewy bodies) in addition to CBS.

\section{Cohort of 150 alien limb patients}

Table 2 summarizes the clinical features associated with alien limb amongst different diagnoses.

Table 3 provides examples of the clinical description of alien limb.

One hundred twenty two subjects had isolated upper extremity alien limb. Thirteen subjects had isolated leg alien limb. Twelve subjects had arm and leg involvement ipsilaterally. Three subjects had bilateral alien limb.

Ten patients with alien limb had a less common primary diagnosis including progressive multifocal leukoencephalopathy $(n=2)$, demyelinating disease not otherwise specified $(n=2)$, progressive dementia not otherwise specified $(n=2)$, posterior reversible encephalopathy syndrome $(n=1)$, corpus callosotomy for intractable seizures $(n=1)$, thalamic dementia $(n=1)$ and intracerebral hemorrhage complicated by hydrocephalus $(n=1)$. Figure 2 depicts cases with radiographic changes associated with the alien limb among different pathologies.

\section{Time from disease onset to alien limb}

Approximate time from first clinical symptom to appearance of alien limb was available for 110 subjects. Forty-six subjects had alien limb within one month of onset of disease. CBS patients presented at a median of 12 months from disease onset; hereditary diffuse leukoencephalopathy with axonal spheroids (HDLS) subjects presented at a median of 9 months while CJD and stroke subjects presented with alien limb at disease onset. See Table 1 for further details.

\section{Location of tumor and strokes with alien limb}

There were 14 cerebrovascular cases and four tumors with alien limb. Table 4 describes the location of the stroke or tumor which resulted in alien limb. Ten cerebrovascular cases were right hemisphere while four were left hemisphere in origin. All cases involved the parietal lobe with occasional frontal, temporal, occipital lobe involvement. Figure 1 highlights the neuroanatomical regions most commonly involved in alien limb caused by stroke. Three of four tumors were right hemisphere while one was bilateral hemispheres. All tumors involved the parietal lobe with two of four also extending into the frontal lobe.

\section{ADRC corticobasal syndrome cohort}

All 44 CBS cases from the ADRC were assessed. Of these, 23 had left limb predominant CBS (21 right limb predominant CBS).

\section{Alien Limb in ADRC corticobasal syndrome cohort}

Half (22) of the 44 CBS patients from the ADRC had alien limb. Median ages of disease onset were similar (age 62 with alien limb, versus 66 without), as was gender (55\% female 
among those with alien limb versus $49 \%$ without alien limb). Notably, the left limb was the affected side in $73 \%(n=16)$ of these 22 ADRC patients with alien limb. This contrasts to only five cases (23\%) affecting the right extremity; one case had both extremities affected simultaneously. Overall, the left side was the predominantly affected side in almost half of the 44 CBS cases $(n=23)$; of these, $70 \%(n=16)$ developed an alien limb in contrast to only $24 \%(\mathrm{n}=5)$ with right-limb-onset CBS. Left sided predominant CBS was significantly associated with the presence of alien limb phenomena $(\mathrm{p}=0.004)$.

In the non-ADRC cohort, predominant left sided alien limb occurred in $65 \%$.

\section{Discussion}

This large cohort of patients with alien limb allows some generalizations regarding neuroanatomic substrates. Thus, focal lesions across all etiologies studied, even if multifocal, consistently affect the parietal lobe contralateral to the alien limb. Moreover, right hemisphere damage is more likely than left to be associated with alien limb. In addition, diseases predominantly affecting white matter, including HDLS, progressive multifocal leukoencephalopathy, posterior reversible leukoencephalopathy syndrome, may exhibit this phenomenon. These findings are consistent with the proposal alien limb phenomena are at least partially related to white matter damage underlying the right parietal cortex, disconnecting it from other cortical areas of the brain such as the contralateral hemisphere or motor areas in the same hemisphere. This would allow for misperception by the other hemisphere, causing descriptions such as in Table 3, loss of awareness of the arm moving, and loss of sensory input from motor cortex when the arm moves.

Although CBS is most frequently associated with alien limb (108 of 150 cases), the differential diagnosis includes a variety of other less common conditions, including CJD (9 patients) and HDLS (5 patients). Furthermore, alien limb phenomena were seen with demyelinating disease, progressive multifocal leukoencephalopathy, and the posterior reversible encephalopathy syndrome.

The timing of the alien limb in the course of the disease can help distinguish amongst the various etiologies. We have previously reported that when alien limb occurs in CJD it is often the initial neurological sign prompting medical evaluation [36]. In contrast, when alien limb typically occurs in CBS or HDLS, the presentation occurs nearly one year into disease onset.

Associated findings are often helpful in the differential diagnosis. The alien limb of CBS occurred commonly with rigidity, apraxia or other key features. Mirror movements, albeit uncommon, suggested CBS and less likely HDLS. Myoclonus occurred in most cases of CJD-related alien limb and never occurred in stroke (e.g., the only other cause of rapid onset alien limb). Intermanual conflict (one hand directly opposes the action of the other) was not common in our patient cohort, documented in only $7 \%$ of CBS cases. Also, note that alien rarely occurs in isolation, in the absence of other neurologic signs, especially in CBS and later-stage CJD (See Table 2). The constellation of signs do not appear particularly specific to a mechanism and conform to findings in each disease without the alien limb.

Accumulation of neurologic signs might be more suggestive of the fulminant pathology of CJD, especially if myoclonus is present.

The right hemisphere as the substrate for the alien limb was a prominent finding in our cohort, consistent across neurodegenerative and lesional causes. This predominance is substantially different from the aforementioned older series; reasons for the difference likely include the large number of cases of CBS and the infrequency of callosal surgeries currently 
performed for seizure control. Thus, in $69 \%$ of our cases the left limb was predominately affected as part of the alien limb syndrome. In the ADRC CBS cohort, in which alien limb was most carefully documented, the left limb was involved $73 \%$ of the time. While CBS appears to occur equally in either hemisphere, alien limb occurs more frequently with left limb (e.g., right hemisphere) onset CBS. The reason for the right hemisphere, left limb predominance is unclear. Perhaps, the right hemisphere involvement predisposes to the sense of estrangement from the limb akin to a neglect phenomenon. Consistent with our results, diffusion tensor imaging in CBS has demonstrated a reduction in the sensorimotor fibers of the hand cortical representations.[7]

Although alien limb is a helpful diagnostic marker of CBS, it was present in only half of our 44 ADRC CBS cases. This frequency is similar to one other large clinical CBS series of referral center patients, where the prevalence in CBS was about 42\%[27]. This is similar to $50 \%$ in the CBS ADRC cohort.

We and others have previously demonstrated that CBS is associated with a spectrum of underlying neurodegenerative disorders, and hence CBS is not an accurate predictor of underlying corticobasal degeneration pathology.[5] Furthermore, cortical or corpus callosum atrophy, or subcortical and periventricular white matter signal changes on MRI, are not specific to CBD.[24] The clinicopathologic findings in this report also demonstrate that alien limb in CBS cases does not accurately predict underlying CBD neuropathology.

Our series has several limitations. The study was retrospective, which was necessary given the rarity of the disorder. The predominance of the so-called posterior phenotype seen in our series precludes us from comparing the anatomy and features of the other alien limb phenotypes to the posterior phenotype. While the limited number of cases of anterior alien limb is a limitation of the study, the large number of posterior variant alien limb cases described highlight the predominance of this variant in clinical practice.

\section{Conclusions}

The alien limb is caused by heterogenous pathologies. This emphasizes the role of affected topography and not necessarily the pathology in determining the presence of alien limb. CBS, stroke and CJD are the most likely etiologies. It is most often associated with right hemisphere, left hemibody involvement. Given the increased awareness of CBS and decline of callosotomy surgeries, the posterior sensory alien limb has become the most prevalent subtype.

\section{Acknowledgments}

Supported by grants P50 AG016574 and the Robert H. and Clarice Smith and Abigail Van Buren Alzheimer s Disease Research Program of the Mayo Foundation.

\section{References}

1. Andre C, Dominques RC. Transient alien hand syndrome: is this a seizure or a transient ischaemic attack? J Neurol Neurosurg Psychiatry. 1996; 60:232-233. [PubMed: 8708666]

2. Ay H, Buonanno FS, Price BH, Le DA, Koroshetz WJ. Sensory alien hand syndrome: case report and review of the literature. J Neurol Neurosurg Psychiatry. 1998; 65:366-369. [PubMed: 9728952]

3. Ball JA, Lantos PL, Jackson M, Marsden CD, Scadding JW, Rossor MN. Alien hand sign in association with Alzheimer's histopathology. J Neurol Neurosurg Psychiatry. 1993; 56:1020-1023. [PubMed: 8410026]

4. Barclay CL, Bergeron C, Lang AE. Arm levitation in progressive supranuclear palsy. Neurology. 1999; 52:879-882. [PubMed: 10078750] 
5. Boeve BF, Maraganore DM, Parisi JE, Ahlskog JE, Graff-Radford N, Caselli RJ, Dickson DW, Kokmen E, Petersen RC. Pathologic heterogeneity in clinically diagnosed corticobasal degeneration. Neurology. 1999; 53:795-800. [PubMed: 10489043]

6. Bogen, J. The callosal syndrome. In: Heilman, KM.; Valenstein, E., editors. Clinical neuropsychology. Oxford University Press; New York: 1979. p. 308-359.

7. Borroni B, Garibotto V, Agosti C, Brambati SM, Bellelli G, Gasparotti R, Padovani A, Perani D. White matter changes in corticobasal degeneration syndrome and correlation with limb apraxia. Arch Neurol. 2008; 65:796-801. [PubMed: 18541800]

8. Brion S, Jedynak CP. Disorders of interhemispheric transfer (callosal disonnection). 3 cases of tumor of the corpus callosum. The strange hand sign. Revue neurologique. 1972; 126:257-266. [PubMed: 4350533]

9. Chan JL, Chen RS, Ng KK. Leg manifestation in alien hand syndrome. Journal of the Formosan Medical Association = Taiwan yi zhi. 1996; 95:342-346. [PubMed: 8935307]

10. Chan JL, Liu AB. Anatomical correlates of alien hand syndromes. Neuropsychiatry, neuropsychology, and behavioral neurology. 1999; 12:149-155.

11. Della Sala S, Marchetti C, Spinnler H. Right-sided anarchic (alien) hand: a longitudinal study. Neuropsychologia. 1991; 29:1113-1127. [PubMed: 1775229]

12. Denny-Brown D, Meyer JS, Horenstein S. The significance of perceptual rivalry resulting from parietal lesion. Brain. 1952; 75:433-471. [PubMed: 13009003]

13. Doody RS, Jankovic J. The alien hand and related signs. J Neurol Neurosurg Psychiatry. 1992; 55:806-810. [PubMed: 1402972]

14. Feinberg TE, Schindler RJ, Flanagan NG, Haber LD. Two alien hand syndromes. Neurology. 1992; 42:19-24. [PubMed: 1734302]

15. Fisher CM. Alien hand phenomena: a review with the addition of six personal cases. Can J Neurol Sci. 2000; 27:192-203. [PubMed: 10975531]

16. Geschwind DH, Iacoboni M, Mega MS, Zaidel DW, Cloughesy T, Zaidel E. Alien hand syndrome: interhemispheric motor disconnection due to a lesion in the midbody of the corpus callosum. Neurology. 1995; 45:802-808. [PubMed: 7723974]

17. Goldberg G, Bloom KK. The alien hand sign. Localization, lateralization and recovery. American Journal of Physical Medicine \& Rehabilitation. 1990; 69:228-238. [PubMed: 2222983]

18. Goldenberg G, Wimmer A, Holzner F, Wessely P. Apraxia of the left limbs in a case of callosal disconnection: the contribution of medial frontal lobe damage. Cortex. 1985; 21:135-148. [PubMed: 3987307]

19. Goldstein K. Zur Lehre von der motorischen Apraxie. Journal für Psychologie und Neurologie. 1908; 11

20. Gorno-Tempini ML, Murray RC, Rankin KP, Weiner MW, Miller BL. Clinical, cognitive and anatomical evolution from nonfluent progressive aphasia to corticobasal syndrome: a case report. Neurocase. 2004; 10:426-436. [PubMed: 15788282]

21. Graff-Radford NR, Welsh K, Godersky J. Callosal apraxia. Neurology. 1987; 37:100-105. [PubMed: 3796825]

22. Hashimoto M, Shimizu J, Shirota Y, Momose Y, Goto J, Takeda K, Tsuji S. Alien hand sign observed at the initial stage of a case of Creutzfeldt-Jakob disease. Rinsho shinkeigaku $=$ Clinical neurology. 2009; 49:109-114. [PubMed: 19348176]

23. Hu WT, Josephs KA, Ahlskog JE, Shin C, Boeve BF, Witte RJ. MRI correlates of alien leg-like phenomenon in corticobasal degeneration. Mov Disord. 2005; 20:870-873. [PubMed: 15799014]

24. Josephs KA, Tang-Wai DF, Edland SD, Knopman DS, Dickson DW, Parisi JE, Petersen RC, Jack CR Jr, Boeve BF. Correlation between antemortem magnetic resonance imaging findings and pathologically confirmed corticobasal degeneration. Arch Neurol. 2004; 61:1881-1884. [PubMed: 15596608]

25. Josephs KA, R MN. Neurological Sign: The Alien Limb. Practical Neurology. 2004; 4:44-45.

26. Kloesel B, Czarnecki K, Muir JJ, Keller AS. Sequelae of a left-sided parietal stroke: posterior alien hand syndrome. Neurocase. 2010; 16:488-493. [PubMed: 20824573] 
27. Kompoliti K, Goetz CG, Boeve BF, Maraganore DM, Ahlskog JE, Marsden CD, Bhatia KP, Greene PE, Przedborski S, Seal EC, Burns RS, Hauser RA, Gauger LL, Factor SA, Molho ES, Riley DE. Clinical presentation and pharmacological therapy in corticobasal degeneration. Arch Neurol. 1998; 55:957-961. [PubMed: 9678313]

28. Leiguarda R, Starkstein S, Berthier M. Anterior callosal haemorrhage. A partial interhemispheric disconnection syndrome. Brain : a journal of neurology. 1989; 112(Pt 4):1019-1037. [PubMed: 2775991]

29. Levine DN, Rinn WE. Opticosensory ataxia and alien hand syndrome after posterior cerebral artery territory infarction. Neurology. 1986; 36:1094-1097. [PubMed: 3736872]

30. MacGowan DJ, Delanty N, Petito F, Edgar M, Mastrianni J, DeArmond SJ. Isolated myoclonic alien hand as the sole presentation of pathologically established Creutzfeldt-Jakob disease: a report of two patients. J Neurol Neurosurg Psychiatry. 1997; 63:404-407. [PubMed: 9328266]

31. Oberndorfer S, Urbanits S, Lahrmann H, Jarius C, Albrecht G, Grisold W. Familial CreutzfeldtJakob disease initially presenting with alien hand syndrome. Journal of neurology. 2002; 249:631632. [PubMed: 12021958]

32. Papagno C, Marsile C. Transient left-sided alien hand with callosal and unilateral frontomesial damage: a case study. Neuropsychologia. 1995; 33:1703-1709. [PubMed: 8745125]

33. Rebeiz JJ, Kolodny EH, Richardson EP Jr. Corticodentatonigral degeneration with neuronal achromasia. Arch Neurol. 1968; 18:20-33. [PubMed: 5634369]

34. Riley DE, Lang AE, Lewis A, Resch L, Ashby P, Hornykiewicz O, Black S. Cortical-basal ganglionic degeneration. Neurology. 1990; 40:1203-1212. [PubMed: 2381527]

35. Rubin M, Graff-Radford J, Boeve B, Josephs KA, Aksamit AJ. The alien limb phenomenon and Creutzfeldt-Jakob disease. Parkinsonism Relat Disord. 2012

36. Rubin M, Graff-Radford J, Boeve B, Josephs KA, Aksamit AJ. The alien limb phenomenon and Creutzfeldt-Jakob disease. Parkinsonism Relat Disord. 2012

37. Trojano L, Crisci C, Lanzillo B, Elefante R, Caruso G. How many alien hand syndromes? Followup of a case. Neurology. 1993; 43:2710-2712. [PubMed: 8255486]

38. Watson RT, Heilman KM. Callosal apraxia. Brain : a journal of neurology. 1983; 106(Pt 2):391403. [PubMed: 6850274]

39. Wilson DH, Reeves A, Gazzaniga M, Culver C. Cerebral commissurotomy for control of intractable seizures. Neurology. 1977; 27:708-715. [PubMed: 560644]

40. Zaidel, E.; Iacoboni, M.; Berman, S.; Zaidel, D.; Bogen, J. Callosal Syndromes. In: Heilman, K.; Valenstein, E., editors. Clinical Neuropsychology. Oxford University Press; New York: 2012. p. 349-416. 
A

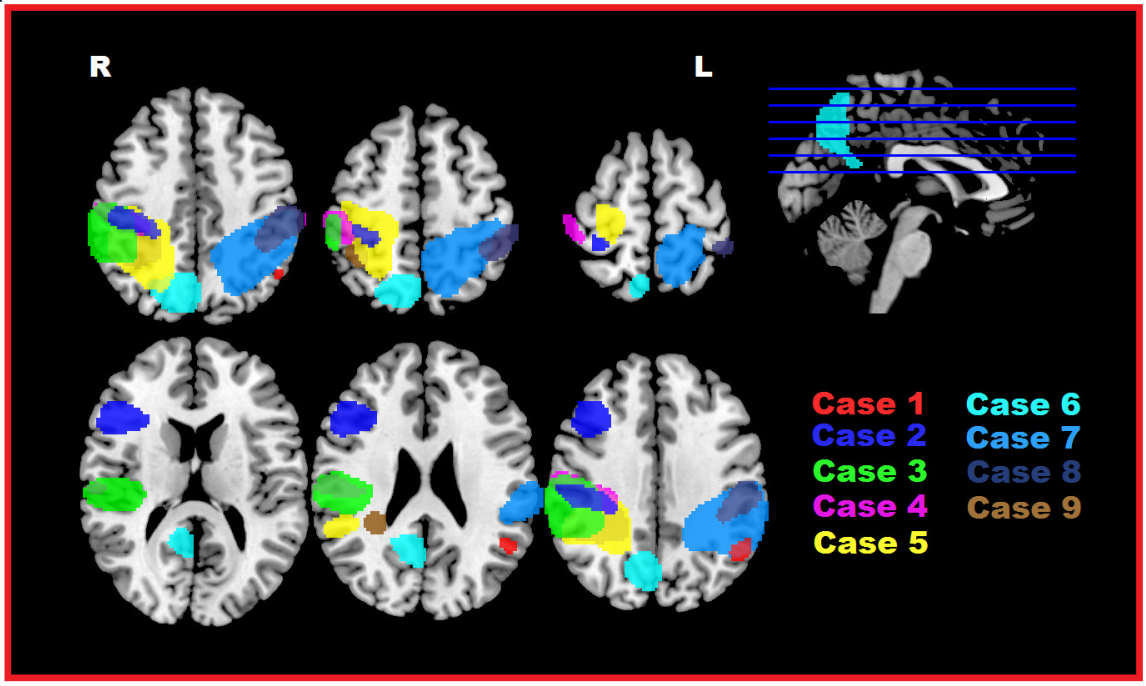

B

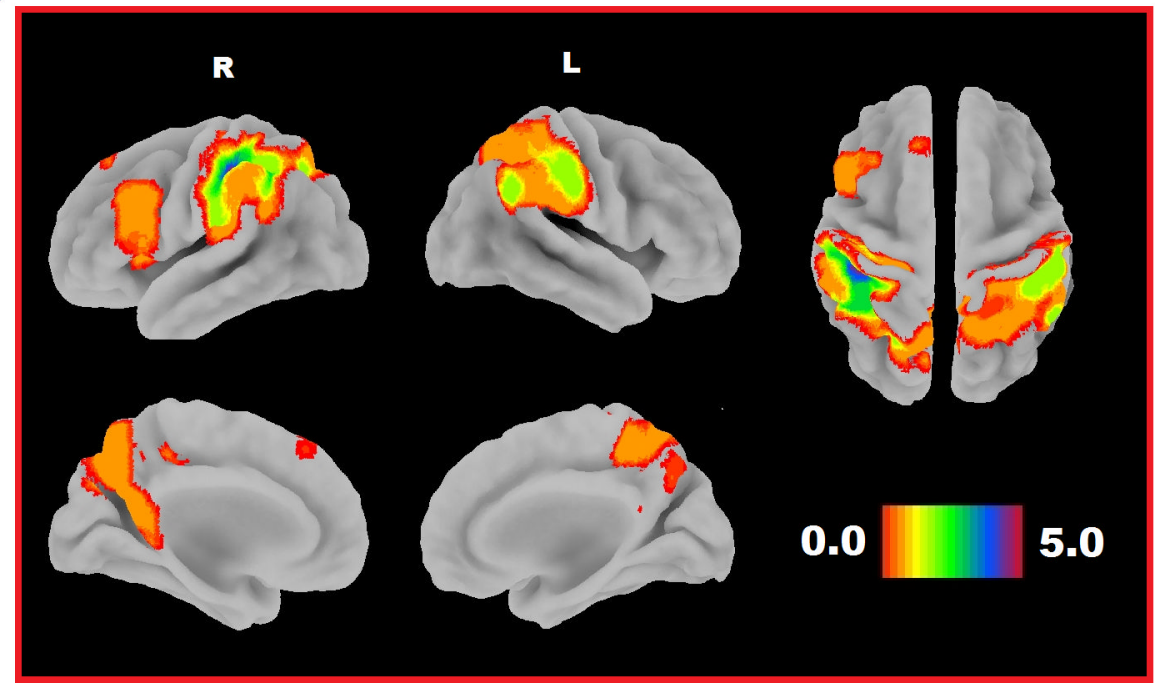

Figure 1.

Regional Infarct Distribution

The location of the zones of infarction are displayed on a template brain and color coded by case (A). The regional frequency of involvement across the brain in each of these 9 cases is displayed by projecting the frequency of lesion overlap onto a surface rendering (B).

Regions of the brain with only a single case involved are on the orange end of the spectrum and the region of the right parietal lobe with the maximum number of cases overlapping (5 of the 9) is on the blue/violet end of the spectrum. These cases correspond with cases 1-9 from Table 4. 

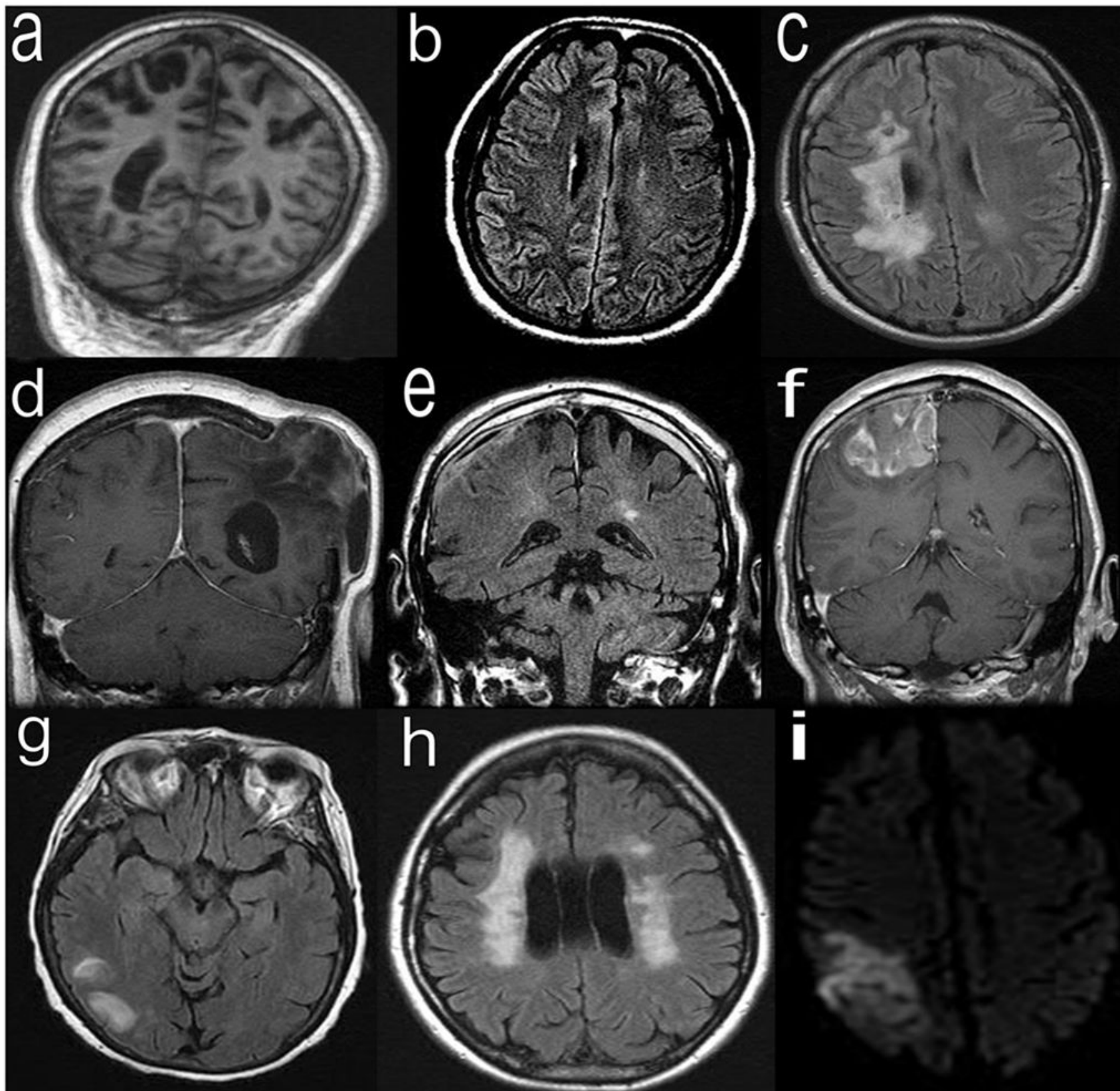

Figure 2.

Montage of select cases demonstrating radiographic changes associated with the alien limb among different pathological processes. The cases are described from top to bottom, from left to right: (a) coronal T-1 MRI demonstrating right parietal atrophy attributed to CBS; (b) axial T-2 weighted FLAIR sequence showing right hemispheric cortical ribboning associated with CJD; (c) T-2 weighted FLAIR sequence showing a large demyelinating lesion in the right posterior corona radiata in a demyelinating disorder not otherwise specified; (d) coronal T-1 waited sequence with prominent left parietal encephalomalacia associated with a now-resolved intracranial hemorrhage; (e) coronal T-2 weighted FLAIR sequence demonstrating bilateral subdural hematomata with subarachnoid hemorrhage and associated cortical irritation of the right parietal lobe; (f) coronal gadolinium-enhanced T-1 weighted sequence showing a right parietal tumor; (g) axial FLAIR image demonstrating 
characteristic changes of the posterior reversible encephalopathy syndrome; (h) axial FLAIR sequence demonstrating bilateral corona radiata abnormalities in hereditary diffuse leukodystrophy with axonal spheroids; (i) axial DWI demonstrating a right parietal infarct. In all cases, the alien limb was contralateral to the afflicted parietal lobe. 


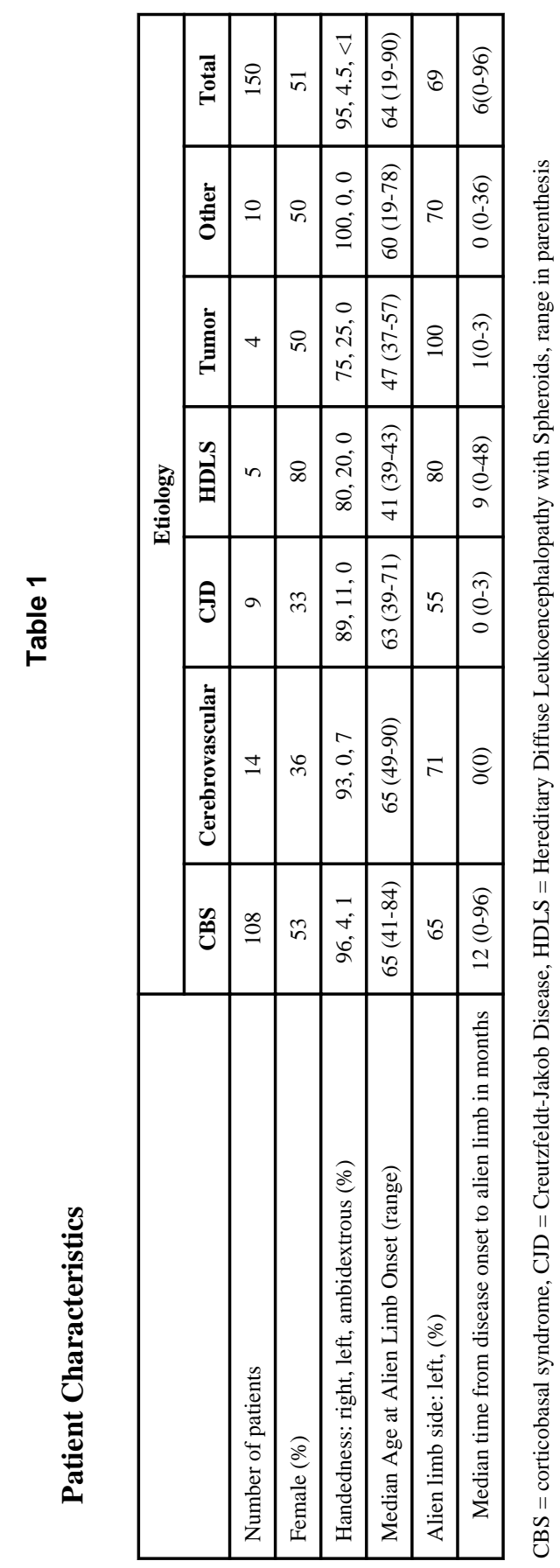

J Neurol. Author manuscript; available in PMC 2014 July 01. 


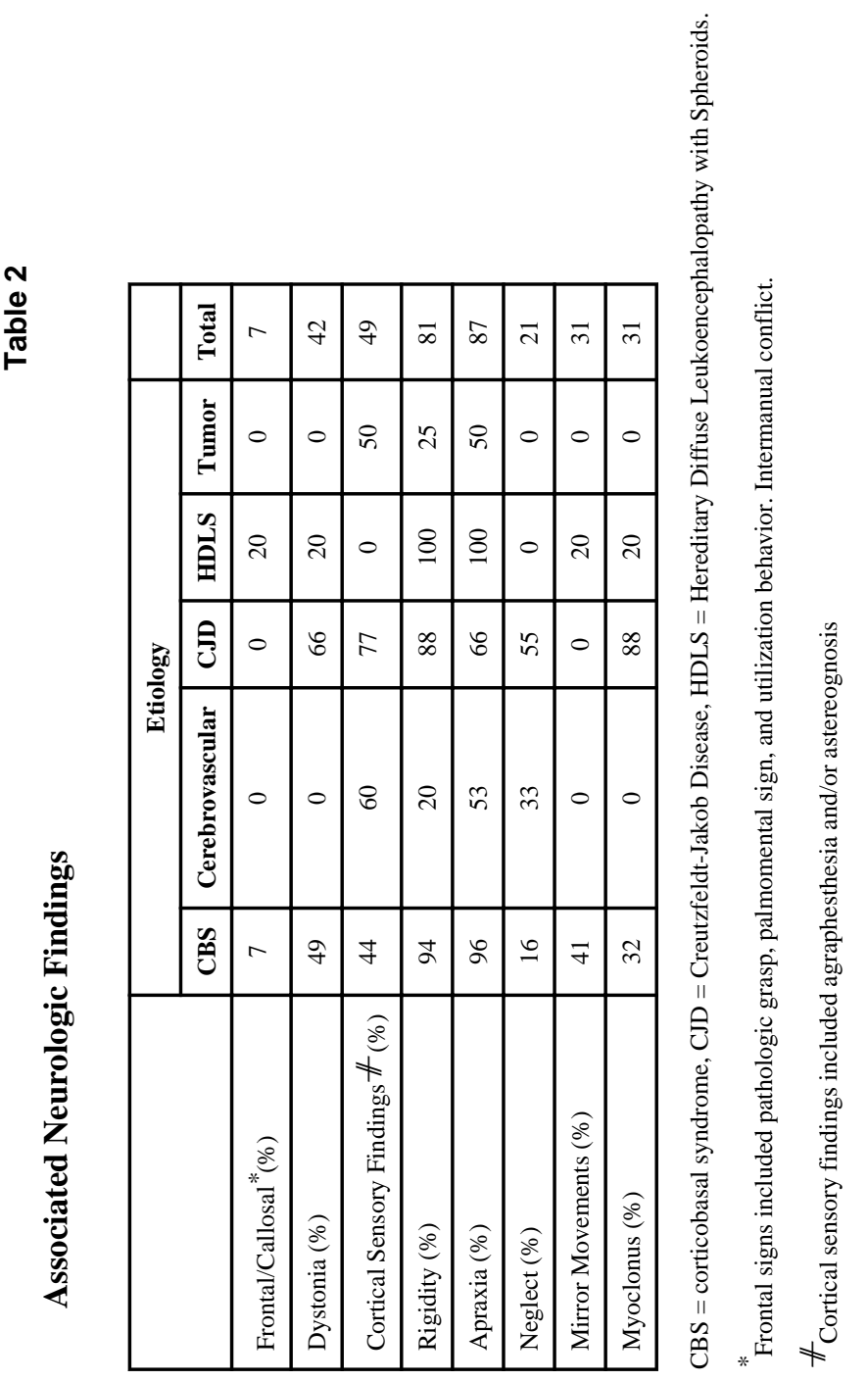

J Neurol. Author manuscript; available in PMC 2014 July 01. 


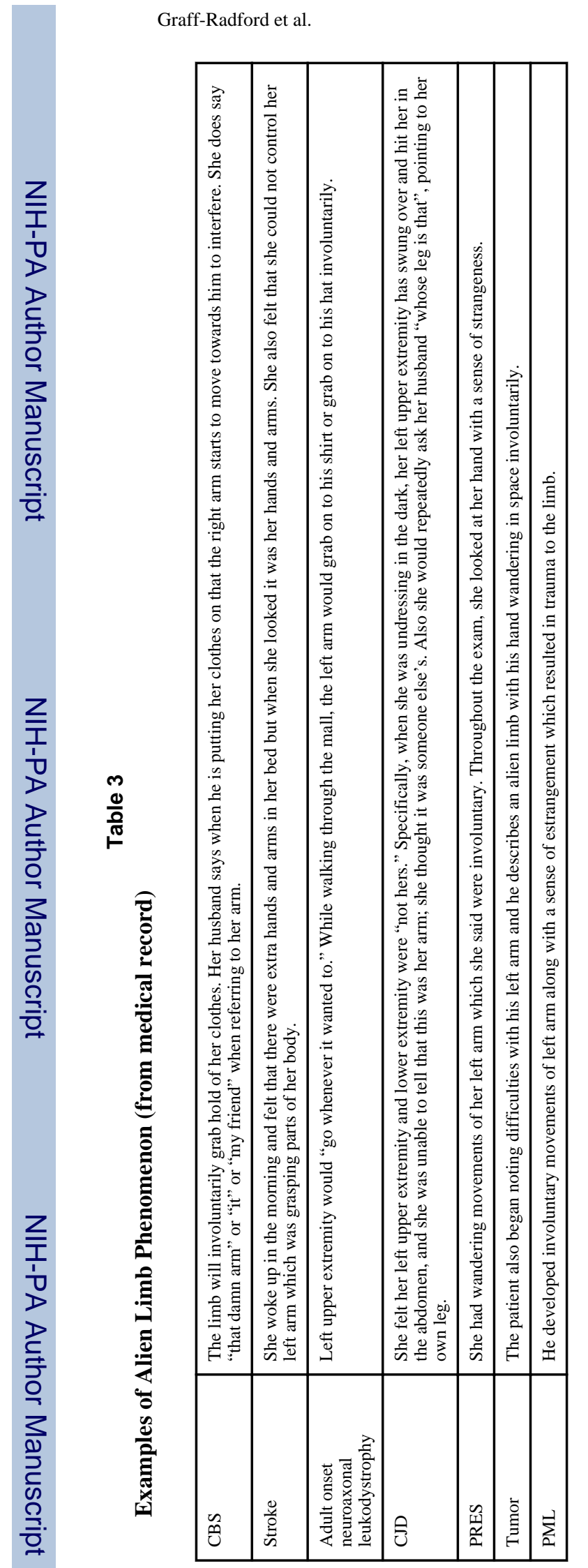

J Neurol. Author manuscript; available in PMC 2014 July 01. 


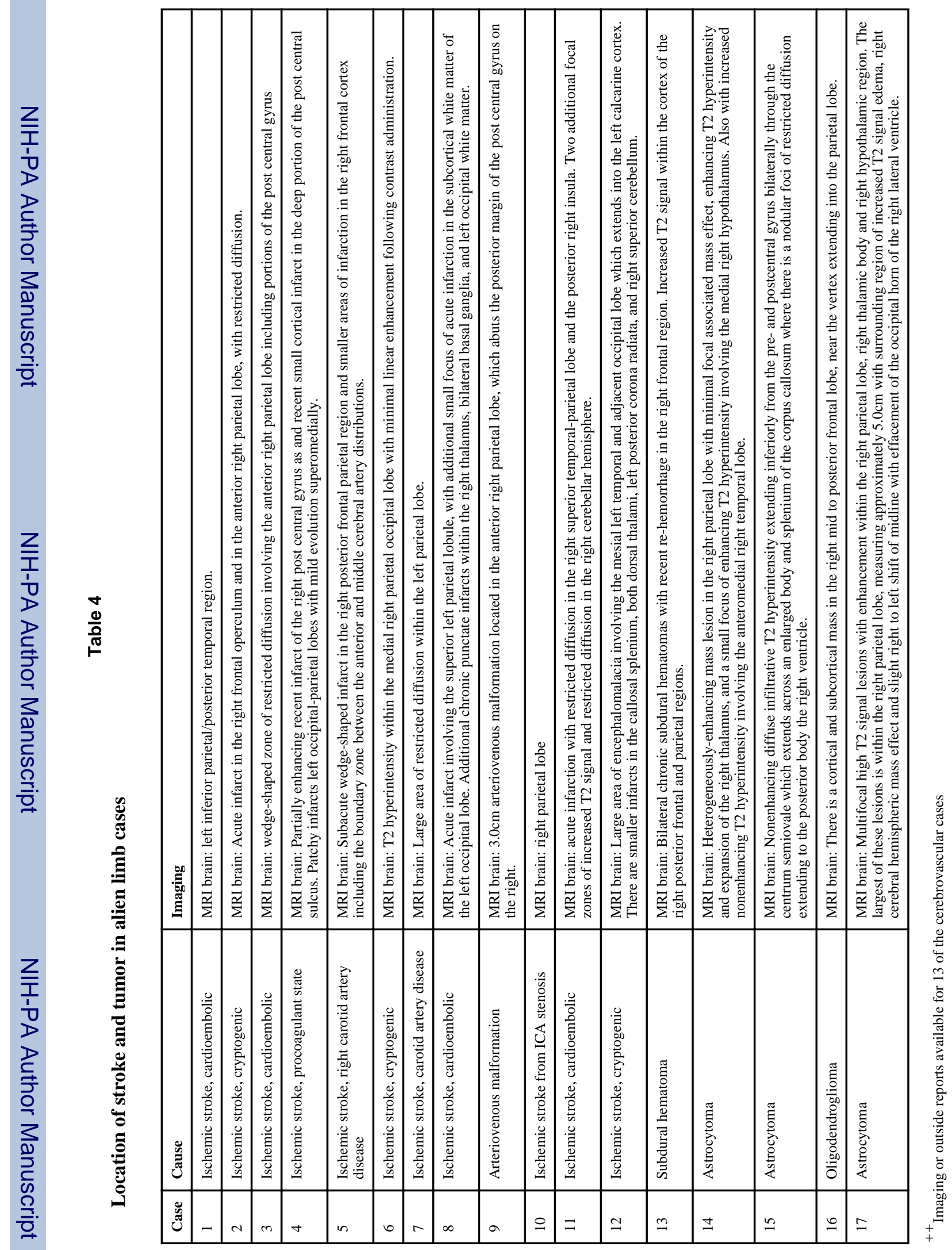

J Neurol. Author manuscript; available in PMC 2014 July 01. 